\title{
COMPARISON OF HABITAT SUITABILITY INDEX MODELS FOR PURPLEBACK FLYING SQUID (Sthenoteuthis oualaniensis) IN THE OPEN SOUTH CHINA SEA
}

\author{
ZHOU, W. F. ${ }^{1 *}-$ XU, H. Y. ${ }^{1,2}-$ LI, A. Z. ${ }^{1,2}-$ CUI, X. S. ${ }^{1}-$ CHEN, G. B. ${ }^{3 *}$ \\ ${ }^{I}$ Key Laboratory of East China Sea \& Ocean Fishery Resources Exploitation and Utilization, \\ Ministry of Agriculture, Shanghai 200090, China \\ ${ }^{2}$ College of Marine Sciences, Shanghai Ocean University, Shanghai 201306, China \\ ${ }^{3}$ South China Sea Fishery Research Institute, Chinese Academy of Fishery Sciences \\ Guangzhou 510300, China \\ *Corresponding authors \\ e-mail: zhouwf@ecsf.ac.cn; chenguobao@scsfri.ac.cn
}

(Received 29 $9^{\text {th }}$ Aug 2018; accepted $7^{\text {th }}$ Nov 2018)

\begin{abstract}
Fisheries resources in inshore regions of the South China Sea (SCS) have been depleted by overfishing. Purpleback flying squid (Sthenoteuthis oualaniensis) fishery is considered as a potential resource in the open SCS. However, little is known about their optimal habitat. Here, habitat suitability index (HSI) models were constructed using the external envelope and arithmetic mean methods to identify optimal habitats of purpleback flying squid. The matched fishery and environmental data (sea surface temperature, sea surface height anomaly, and ocean net primary productivity data) were collected from 2010 to 2014 in the open SCS. We calculated catch per unit effort (CPUE) and fishing effort to estimate the suitability index. The estimated suitable ranges for sea surface temperature, sea surface height anomaly, and net primary productivity were $27.1-30.4{ }^{\circ} \mathrm{C}, 0-0.15 \mathrm{~cm}$, and $236.2-492.8 \mathrm{mg} \mathrm{C} / \mathrm{m}^{2} \mathrm{~d}$ based on the HSI model incorporating fishing effort. The corresponding suitable ranges estimated by the HSI model incorporating CPUE were $27.4-30.7^{\circ} \mathrm{C}, 0.03-0.18 \mathrm{~cm}$, and $238.4-475.5 \mathrm{mg} \mathrm{C} / \mathrm{m}^{2} \mathrm{~d}$, respectively. When HSI values for 2014 were $>0.6$, the HSI model based on fishing effort explained $72.6 \%$ of the fishing effort and the average CPUE was $4.29 \mathrm{t} / \mathrm{d}$. The HSI model based on CPUE explained $66.39 \%$ of the fishing effort for 2014 and the average CPUE was $4.23 \mathrm{t} / \mathrm{d}$. The accuracy of the forecasting model based on fishing effort was higher than that based on CPUE. This HSI model can be used to aid in the management and conservation of purpleback flying squid in the SCS.
\end{abstract}

Keywords: ocean remote sensing, SCS, ecological model, fishery resources, catch per unit effort

\section{Introduction}

Commercial fisheries in the South China Sea (SCS) contribute to the tota China's marine fishery by 27.4\% (Qiu et al., 2008). However, fisheries resources have depleted because of overfishing in coastal regions of the SCS. More fishing activities spread to the open SCS, capturing cephalopods as main targets (Chen et al., 2013). Specifically, purpleback flying squid (Sthenoteuthis oualaniensis), a cephalopod species inhabiting warm waters, is widely distributed in the open SCS (Siriraksophon et al., 2001a, 2011b; Zhang et al., 2015b). As a potential commercial fishery resources for sustainable exploitation, the available annual capture is estimated between 1.3 and 2.0 million tons in the SCS, while the actual capture was 0.05 million tons in 2011 (Siriraksophon et al., 2001a; Ji et al., 2015). Thus, purpleback flying squid fishery will play a crucial role in the SCS's fishery. Although it has been considered to support potentially a more robust fishery in the open SCS because of its abundance, short life span, fast growth rate, high 
fecundity, and high nutritional value (Chen et al., 2013; Zhang et al., 2015b; Yu et al., 2012), there is no complete and scientific research about the relationship between purpleback flying squid and environmental factors in the open SCS. It is crucial to sustain and protect the fishery in the SCS under environmental changes in future (Ji et al., 2015).

Commercial fisheries data at large-scale are available as an important index to understand status of fishery resource (Hilborn and Walters, 1992). Catch and effort from commercial fishery were commonly used to develop models to predict distribution of fish species (Morris and Ball, 2006; Tian, et al., 2009). The catch per unit effort (CPUE) is commonly used to analyze the relationship between environmental variables and fish habitat, but commercial fisheries CPUE is influenced by other variables. Thus CPUE must be standardized to be a reliable abundance index (Zhang et al., 2015a). In addition, comparison of fishing effort and CPUE as an abundance index are be necessary especial for purpleback flying squid with high swimming speed (Tian et al., 2009; Zhang et al., 2015a; Pedro et al., 2006).

Habitat suitability index (HSI) model is suitable for describing and evaluating habitat qualities and species distributions (US Fish and Wildlife Service, 1981), including management of species, ecological environmental restoration (Duel et al., 1996; Gore and Hamilton, 1996; Maddock, 1999), and forecasting of central fishing grounds (Tian et al., 2009; Li et al., 2015). In addition, it has been applied to investigate relationships between fishing ground and relevant environmental factors effecting distribution of flying squid species in northwestern Indian Ocean ( $\mathrm{Yu}$ et al., 2012), northwestern Pacific Ocean (Tian et al., 2009). Currently, large variation in spatial distribution of capture for purpleback flying squid fishery in the SCS existed, with overfishing in the coastal regions and underutilization in the open regions.

The HSI model for purpleback flying squid in the western Indian Ocean was applied to construct relationships between its catch and habitat factors (Chen et al., 2007), while, due to the dataset with short time series and mere catches of Chinese's vessels they used, their study is limited to illustrating general theoretical relationships to explore and protect this species. Thus, more accurate estimations are needed to identify the suitable habitat for purpleback flying squid. To aim this, using the HSI model, a full and specific fishery dataset (2010-2014) in the SCS were used to investigate optimal habitat with high production and corresponding habitat factors, including sea surface temperature (SST), sea surface height anomaly (SSHA), and net primary productivity (NPP). Additionally, the final goal is to effectively develop purpleback flying squid fishery by predicting locations of fishing grounds of purpleback flying squid in the open SCS.

\section{Material and methods}

\section{Data}

Commercial fishery data of purpleback flying squid were obtained from the SCS's dynamic fishing and monitoring network. This data recorded the date, location, catches and number of nets for each fishing activities from 2010 to 2014. In addition, the full ranges of these activities covered the area of $105^{\circ}-120^{\circ} \mathrm{E}, 5-25^{\circ} \mathrm{N}$ (Fig. 1). Changes in monthly number of nets for purpleback flying squid over this time period were illustrated in Figure 2. 


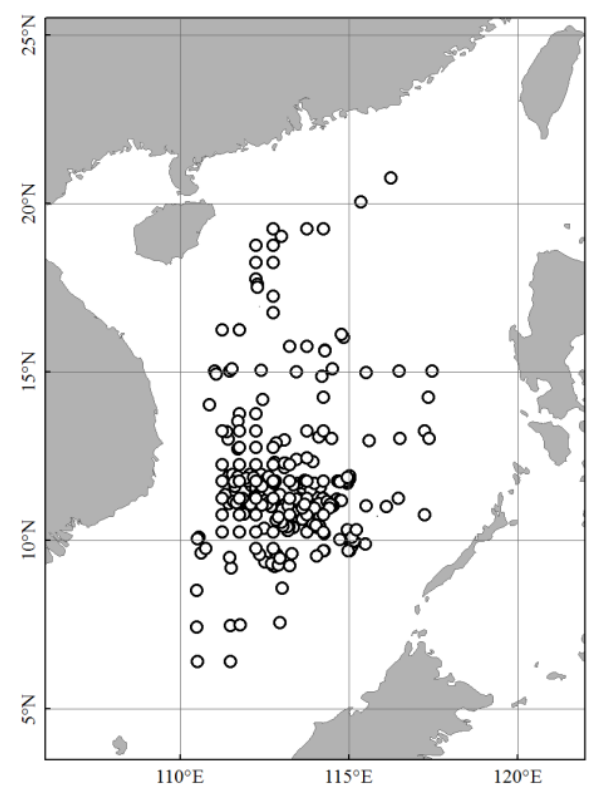

Figure 1. The location of fishery data collected during 2010-2014 in the open South China Sea

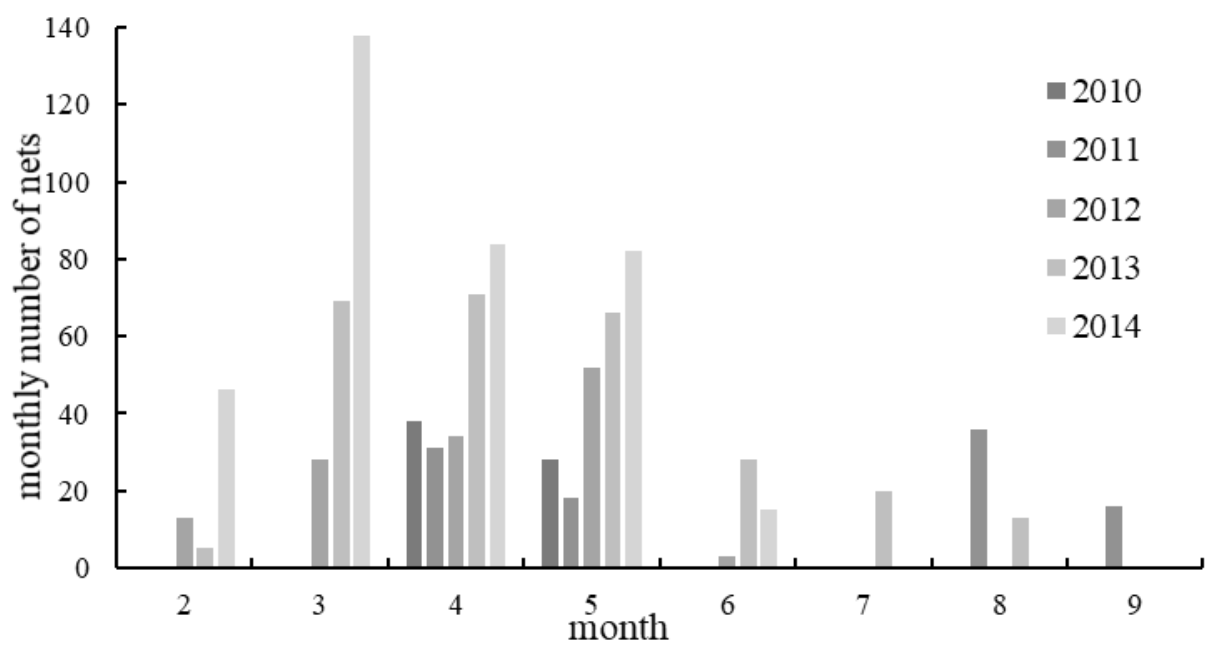

Figure 2. Changes in monthly number of nets for purpleback flying squid during 2010-2014 in the open South China Sea

Environmental data included SST, SSHA and NPP. The daily SST data were derived by the remote sensing system research company located in Northern California (http://www.remss.com/measurements/sea-surface-temperature). These data were the optimally interpolating SST products merging from microwave and infrared SST maps at an approximately $9 \times 9 \mathrm{~km}$ resolution. The daily SSHA images were downloaded from Centre National d'Etudes Spatiales (CNES) data center (http://www.aviso.altimetry.fr/en/data/products/sea-surface-height-products.html), and merged based on altimeter data (Topex/Poseidon, JASON-1, Jason-2, Envisat, ERS-1, ERS-2, and Cryosat-2) at a $0.25 \times 0.25$ degree resolution. The 8 day average global ocean net primary production (NPP) data products were obtained from the Oregon State University 
(http://orca.science.oregonstate.edu/1080.by.2160.monthly.hdf.vgpm.m.chl.m.sst.php), and were estimated based on MODIS at a 1/6 degree spatial resolution. All environmental data covered the full ranges of fishing grounds over the entire study period.

\section{Methods}

\section{Data processing}

All environmental data were processed at a $0.5 \times 0.5$ degree resolution and matched to the ranges of the fishing grounds using MATLAB 2012b (The MathWorks, Inc., Natick, Massachusetts, United States).

The nominal catch per unit effort (CPUE) for each cell was calculated in Equation 1 as follows:

$$
\text { CPUE }_{i, j}=\frac{\text { Catch }_{i, j}}{\text { effort }_{i, j}}
$$

where Catch $_{i, j}$ and effort ${ }_{i, j}$ is the total weight of catches, and numbers of nets for the ith and jth cell, respectively.

The nominal CPUE in Equation 1 hardly indicates the true abundance of fishery over the entire fishing geographical locations and periods, because many factors can affect their accuracies (Zhang et al., 2015a; Maunder et al., 2006). Thus, to remover these effects, a standardized CPUE was computed using a support vector machine method following Yang et al. (2015). See Yang et al. (2015) for the detail processes for standardizing CPUE.

\section{Building a suitability index (SI) model}

A number of models and methods have been used to forecast the location of fishing grounds (e.g., Lee et al., 2005; Grant et al., 1988; Georgakarakos et al., 2006; Skov et al., 2008). HSI models appear to perform well for identifying the location of purpleback flying squid fishing grounds (Tian et al., 2009; Li et al., 2015). A number of methods have been used to calculate the Suitability index (SI) in HSI models, including the external envelope method, BP neural networks, and non-linear regression (Chen et al., 2009; Yu et al., 2012; Frenkel et al., 2017). Among these, the external envelope method appears more suited for cephalopoda (Fang et al., 2014; Gurkan, 2016).

Effort can be used as an index of fish presence or provide general information on the utilization of fishery resources (Andrade et al., 1999; Swamy et al., 2017). And we want to know whether swimming speed has an effect on catch, we adopted effort as a variable to build model. The correlation between effort and Standardized CPUE was analyzed, $\mathrm{P}$ value is 0.7724 , which means there is no significant correlation between effort and standardized CPUE in other words.

Thus, we modeled the relationships between effort or standardized CPUE, and SST, SSHA, and NPP using the external envelope method during the years 2010-2013. When effort or standardized CPUE is highest, the SI value is 1, and when effort or standardized CPUE is 0, the SI value is 0 (Mohri et al., 1999). We calculated SI using Equations 2 and 3: 


$$
\begin{gathered}
S I_{\text {effort }}=\frac{\text { effort }}{\text { effort }_{\text {max }}} \\
S I_{C P U E}=\frac{C P U E_{i, j}}{C P U E_{\text {max }}}
\end{gathered}
$$

where $S I_{\text {effort }}\left(S I_{C P U E}\right)$ represents SI values computed based on effort (CPUE), effort $\mathrm{i}_{\mathrm{i} j}$ $\left(C P U E_{\mathrm{ij}}\right)$ represents the effort (CPUE) at the location represented by longitude $\mathrm{i}$ and latitude $\mathrm{j}$, and effort $_{\max }\left(C P U E_{\max }\right)$ represents the maximum of all effort (CPUE) data.

\section{Building the HSI model}

Prior research suggests that the arithmetic mean method (AM) is a better predictor of the fishing ground location than the geometric mean method (Li et al., 2015; MejiaSanchez et al., 2018). Thus, we used the AM method to calculate HSI values during HSI model establishment. The HSI was calculated using Equations 4 and 5:

$$
\begin{gathered}
H S I_{\text {effort }}=\left(S I_{S S T_{-} \text {effort }}+S I_{S S H A_{-} \text {effort }}+S I_{N P P_{-} \text {effort }}\right) / 3 \\
H S I_{C P U E}=\left(S I_{S S T_{-} C P U E}+S I_{S S H A_{-} C P U E}+S I_{N P P_{-} C P U E}\right) / 3
\end{gathered}
$$

where $H S I_{\text {effort }}$, and $H S I_{C P U E}$ represent HSI values calculated based on effort and CPUE, respectively. $S I_{\text {SST_effort, }} S I_{\text {SSHA_effort, }}$ and $S I_{\text {NPP_effort }}$ represent SI values computed based on effort using SST, SSHA, or NPP as the variable, respectively. SISST_CPUE, SISSHA_CPUE, and SINPP_CPUE represent SI values computed based on CPUE using SST, SSHA, or NPP as the variable, respectively.

\section{HSI model verification and comparison}

The HSI values in 2014 were obtained using the models described above, and divided into five classes: $0-0.2,0.2-0.4,0.4-0.6,0.6-0.8$, and $0.8-1$ (Yu et al., 2012; Li et al., 2015). Then, the cumulative effort and catch was counted separately in each class (Tian et al., 2009). The habitats with HSI values $>0.6$ were considered to represent habitat near the center of the fishing grounds (Yu et al., 2012; Yuan et al., 2017). Percentages of effort with HSI values $>0.6$ computed by HSI models based on effort and CPUE, respectively were compared to get an optimal model for studying habitant of purpleback flying squid.

\section{Results}

\section{Relationships between fishing effort, CPUE, and environmental factors}

Figure 3 illustrated relationships between the SI based on fishing effort (Fig. 3a-c) and CPUE (Fig. $3 d-f$ ) and environmental factors. For the SI from the fishing effort, the optimal ranges for SST, SSHA, and NPP are 27.1-30.4 ${ }^{\circ} \mathrm{C}, 0-0.15 \mathrm{~cm}$, and $236.2-$ $492.8 \mathrm{mg} \mathrm{C} / \mathrm{m}^{2} \mathrm{~d}$., respectively. For the SI from CPUE, the corresponding suitable ranges are $27.4-30.7^{\circ} \mathrm{C}, 0.03-0.18 \mathrm{~cm}$, and $238.4-475.5 \mathrm{mg} \mathrm{C} / \mathrm{m}^{2} \mathrm{~d}$, respectively. 

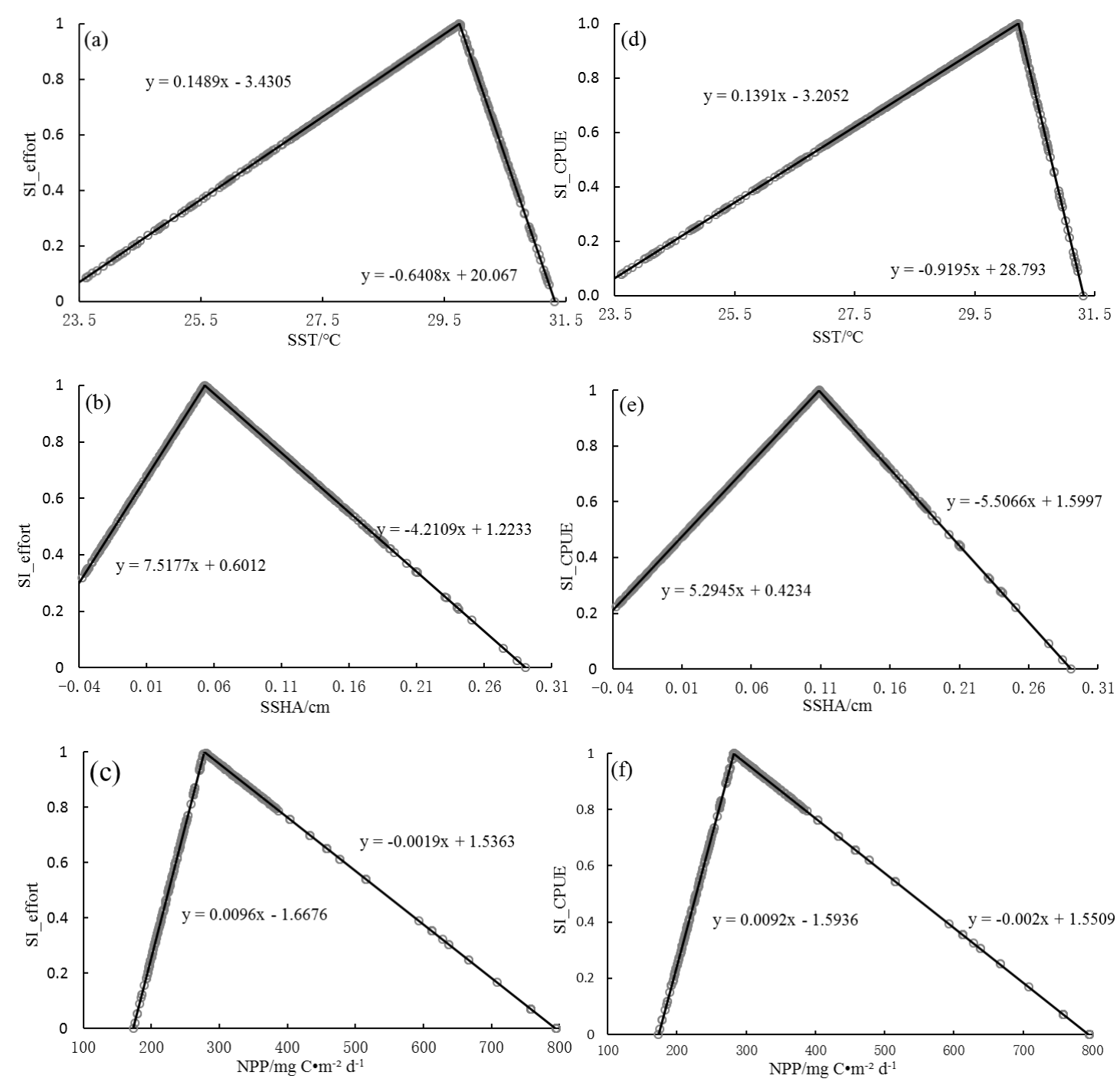

Figure 3. The suitability index curves based on fishing effort and catch per unit effort (CPUE) during 2010-2013 in the open South China Sea

\section{Models comparisons}

Regions with a HSI value greater than 0.6 , are considered as the preferred fishing grounds for purpleback flying squid in the open SCS. Thus, in this study, $72.45 \%$ of the catches and $71.88 \%$ of fishing effort in whole fishing grounds is with HSI over 0.6 based on HSI model from fishing effort during the period from 2010 to 2013 (Table 1), while, $68.86 \%$ of the catches and $70.24 \%$ of fishing effort in whole fishing grounds is with HSI over 0.6 based on HSI model from CPUE.

\section{Verification and comparison of fishing ground distribution}

When HSI is $>0.6$, the HSI model based on fishing effort verifies fishing effort in 2014 with $72.6 \%$ accuracy and the average CPUE is $4.29 \mathrm{t} / \mathrm{d}$. Similarly, the model based on CPUE is $66.39 \%$ accurate and the average CPUE is $4.23 \mathrm{t} / \mathrm{d}$ (Table 2). The accuracy of the forecasting model based on fishing effort is higher than that based on CPUE. Thus, the HSI model based on fishing effort is the best available model for 
forecasting the distribution of habitats suitable for purpleback flying squid in the open SCS. The precision of this forecasting model is $72 \%$ when actual fishing effort can be used as an index to judge the accuracy of main fishing grounds. Catch and HSI values of SST, SSHA and NPP in 2014 were calculated using above HSI model based on fishing effort illustrated in Figure 4.

Table 1. Percent of catch and fishing effort explained by the HSI models based on fishing effort or catch per unit effort (CPUE)

\begin{tabular}{c|c|c|c|c|c|c}
\hline \multirow{2}{*}{ HSI } & \multicolumn{2}{|c|}{ HSI model based on fishing effort } & \multicolumn{3}{c}{ HSI model based on CPUE } \\
\cline { 2 - 7 } & $\begin{array}{c}\text { Percentage } \\
\text { of catch /\% }\end{array}$ & $\begin{array}{c}\text { Percentage of } \\
\text { fishing effort /\% }\end{array}$ & $\begin{array}{c}\text { Average } \\
\text { CPUE /(t/d) }\end{array}$ & $\begin{array}{c}\text { Percentage } \\
\text { of catch /\% }\end{array}$ & $\begin{array}{c}\text { Percentage of } \\
\text { fishing effort /\% }\end{array}$ & $\begin{array}{c}\text { Average } \\
\text { CPUE /(t/d) }\end{array}$ \\
\hline $0-0.2$ & 4.77 & 4.39 & 1.73 & 5.08 & 4.51 & 1.79 \\
$0.2-0.4$ & 7.46 & 8.73 & 1.36 & 14.02 & 12.07 & 1.85 \\
$0.4-0.6$ & 15.32 & 15.00 & 1.63 & 12.04 & 13.18 & 1.45 \\
$0.6-0.8$ & 22.31 & 24.96 & 1.42 & 23.91 & 24.60 & 1.55 \\
$0.8-1$ & 50.14 & 46.92 & 1.70 & 44.95 & 45.64 & 1.57 \\
\hline
\end{tabular}

We used sea surface temperature (SST), sea surface height anomaly (SSHA), net primary productivity (NPP) as explanatory variables for the years 2010-2013 in the open South China Sea

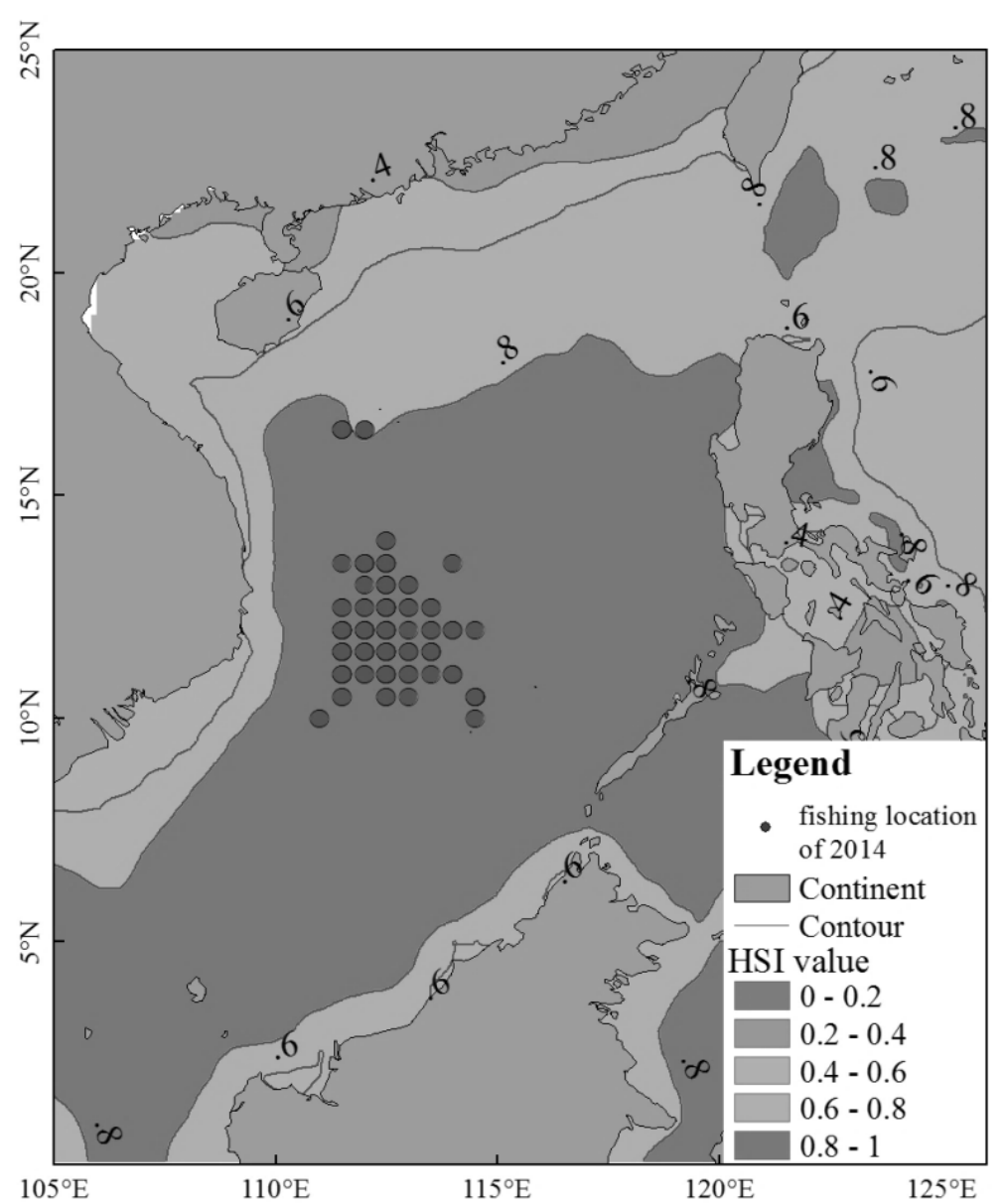

Figure 4. Distribution of projected HSI values and fishing location of 2014 in the open South China Sea 
Table 2. Percentage of catch and fishing effort in 2014 explained by the HSI model based on fishing effort and catch per unit effort (CPUE)

\begin{tabular}{c|c|c|c|c|c|c}
\hline \multirow{2}{*}{ HSI } & \multicolumn{2}{|c|}{ HSI model based on fishing effort } & \multicolumn{3}{c}{ HSI model based on CPUE } \\
\cline { 2 - 7 } & $\begin{array}{c}\text { Percentage } \\
\text { of catch /\% }\end{array}$ & $\begin{array}{c}\text { Percentage of } \\
\text { fishing effort /\% }\end{array}$ & $\begin{array}{c}\text { Average } \\
\text { CPUE /(t/d) }\end{array}$ & $\begin{array}{c}\text { Percentage } \\
\text { of catch /\% }\end{array}$ & $\begin{array}{c}\text { Percentage of } \\
\text { fishing effort /\% }\end{array}$ & $\begin{array}{c}\text { Average } \\
\text { CPUE /(t/d) }\end{array}$ \\
\hline $0-0.2$ & 0.88 & 1.28 & 1.41 & 0.51 & 0.73 & 1.43 \\
$0.2-0.4$ & 2.89 & 5.30 & 1.11 & 5.84 & 7.31 & 1.63 \\
$0.4-0.6$ & 19.05 & 20.82 & 1.87 & 24.01 & 25.57 & 1.92 \\
$0.6-0.8$ & 27.85 & 27.85 & 2.04 & 26.94 & 28.13 & 1.95 \\
$0.8-1$ & 49.32 & 44.75 & 2.25 & 42.70 & 38.26 & 2.28 \\
\hline
\end{tabular}

We used sea surface temperature (SST), sea surface height anomaly (SSHA), net primary productivity (NPP) as explanatory variables for the years 2014 in the open South China Sea

\section{Discussion}

Changes in the fishing ground were impacted by multi-factors, e.g. life history for each fish species, supply of food, and changes in environmental factors (Chen et al., 2007; Yan et al., 2012). Among these factors, the later one can directly affect fish's life cycle by, e.g. food supplication or distribution of prey resources (Yu et al., 2016). For detail, SST can determine the general distribution patterns by affecting the processes of birth, reproduction, and migration (Ji et al., 2015; Zhang et al., 2015a).

Sea surface height (SSH) data reflects the influence of the direction and velocity of water flow, the interaction of cold and warm water masses, and other dynamic environmental variables (Shao et al., 2008; Song, 2014), which, in turn influence the distribution of fauna and the formation of fishing grounds (Shao et al., 2008). SSHA reflects the difference between sea surface height and mean sea level. Thus, SSH or SSHA data are often used in assessments of the relationship between environmental factors and fisheries (Song, 2014). NPP data have been used to model tuna, mackerel, and squid resources in other regions (Zainuddin et al., 2006; Yu et al., 2016). To our knowledge, this is the first study to evaluate the utility of using NPP to predict purpleback flying squid distribution in the open SCS. Our analysis suggests that it is feasible to build an HSI model based on SST, SSHA, and NPP to describe the fishing distribution of purpleback flying squid in the open SCS. For the period 2010-2013, the suitable range of SST, SSHA, and NPP was $27.1-30.4{ }^{\circ} \mathrm{C}, 0-0.15 \mathrm{~cm}$, and $236.2-492.8$ $\mathrm{mg} \mathrm{C} / \mathrm{m}^{2} \mathrm{~d}$, respectively. This is consistent with prior studies that estimated the range of suitable SST for purpleback flying squid was $27-29^{\circ} \mathrm{C}$ in the northwestern waters of the Indian Ocean (Yu et al., 2012; Luo et al., 2015) and an optimal SSHA of 0.00 in the northwest Indian Ocean (Shao et al., 2008).

\section{Conclusions}

\section{Analysis of the HSI models}

Because of sovereignty disputes in the SCS, the spatial scale of fishing is limited. To ensure forecasting accuracy, we used daily records of environmental data rather than monthly. Additionally, because of the influence of atmospheric climate on oceanic variables, the environmental factors that exhibit high spatial and temporal resolution with respect to the distribution of purpleback flying squid should also reflect the 
influence of season on distribution of purpleback flying squid. We compared two HSI models, one based on fishing effort and the other based on CPUE using the external envelope method. The precision of the HSI model based on fishing effort (72.6\%) was higher than the HSI model based on CPUE (66.39\%). Thus, the HSI model based on fishing effort appears to provide more realistic results when his values $>0.6$.

\section{Improvement of the HSI model}

Although the HSI model described in this paper has high forecast precision, it could be improved by increasing the amount of fishing data used to parameterize the model. Additionally, although we used three commonly referenced environmental variables, purpleback flying squid may be influenced by other environmental factors that were not considered (Jia et al., 2004; Yu et al., 2012). Thus, we recommend developing the current HSI model to incorporate more fishery data and test the influence of other environmental factors (e.g. currents, sea surface salinity) and interactions among variables.

Acknowledgements. This research was financially supported by Project 31602206 supported by National Natural Science Foundation of China, the Natural Science Foundation of Shanghai under contract NO. 16ZR1444700, the Key Technologies R\&D Program of China under contract No. 2013BAD13B06 and Project NO.2016T05 Supported by Special Scientific Research Funds for Central Non-profit Institutes (East China Sea Fisheries Research Institute). And we also acknowledge China Scholarship Council (File No.201803260014).

\section{REFERENCES}

[1] Andrade, H. A., Carlos, A. E. (1999): Skipjack tuna fishery in relation to sea surface temperature off the southern Brazilian coast. - Fisheries Oceanography 8(4): 245-254.

[2] Chen, G., Zhang, J., Yu, J., Fan, J., Fang, L. (2013): Hydroacoustic scattering characteristics and biomass assessment of the purpleback flying squid Sthenoteuthis oualaniensis (Lesson, 1830) from the deepwater area of the South China Sea. - Journal of Applied Ichthyology 29: 1447-1452.

[3] Chen, X., Liu, B., Tian, S, Qian, W. (2007): Fishery biology of purpleback squid, Sthenoteuthis oualaniensis, in the northwest Indian Ocean. - Fisheries Research 83(1): 98-104.

[4] Chen, X., Li, G., Feng, B., Tian, S. (2009): Habitat suitability index of chub mackerel (Scomber japonicus) from July to September in the East China Sea. - Journal of Oceanography 65: 93-102.

[5] Duel, H. B., Pedroli, W. E., Laane, M. (1996): The Habitat Evaluation Procedure in the Policy Analysis of Inland Waters in the Netherlands: Towards Ecological Rehabilitation. - In: Leclerc, M., Carpa, H., Valentin, S., et al. (eds.) Ecohydraulics 2nd International Symposium on habitat Hydraulics, Quebec, pp. 619-630.

[6] Fang, X., Chen, X., Ding, Q. (2014): Optimization fishing ground prediction models of dosidicus gigas in the high sea off Chile based on habitat suitability index. - Journal of Guangdong Ocean University 34(4): 67-73.

[7] Frenkel, O., Jaiswal, A. K., Elad, Y., Lew, B., Kammann, C., Graber, E. R. (2017): The effect of biochar on plant diseases: what should we learn while designing biochar substrates? - Journal of Environmental Engineering and Landscape Management 25(2SI): 105-113. 
[8] Georgakarakos, S., Koutsoubas, D., Valavanis, V. (2006): Time series analysis and forecasting techniques applied on loliginid and ommastrephid landings in Greek waters. Fisheries Research 78: 55-71.

[9] Gore, J. A., Hamilton, S. W. (1996): Comparison of flow-related habitat evaluations downstreams of low-head weirs on small and large fluvial ecosystems. - Regulated Rivers Research \& Management 12: 459-469.

[10] Grant, W. E., Matis, J. H., Miller, W. (1988): Forecasting commercial harvest of marine shrimp using a Markov chain model. - Ecol. Modell. 43: 183-193.

[11] Gurkan, A. (2016): Biotope mapping in an urban environment for sustainable urban development - a case study in southern part of turkey. - Applied Ecology and Environmental Research 14(4): 493-504.

[12] Hilborn, R., Walters, C. (1992): Quantitative Fisheries Stock Assessment, Choice, Dynamics, And Uncertainty. - Chapman and Hall, New York.

[13] Ji, S., Zhou, W., Chen, T., Chen, G. (2015): On the forecast and analysis of fishing grounds in the open South China Sea. - Fishery Information \& Strategy 30(2): 98-105.

[14] Jia, X., Li, Y., Li, C. (2004): Fishery Ecological Environment and Fishery Resources in the Exclusive Economic Zone and Continental Shelf of the South China Sea. - Science Press, Beijing.

[15] Lee, P. F., Chen, I. C, Tzeng, W. N. (2005): Spatial and temporal distribution patterns of Bigeye tuna (thunnus obesus) in the Indian Ocean. - Zoological Studies 44(2): 260-270.

[16] Li, G., Cao, J., Zou, X., Chen, X., Runnebaum, J. (2015): Modeling habitat suitability index for chilean jack mackerel (trachurus murphyi) in the south east pacific. - Fisheries Research 178: 47-60.

[17] Luo, G., Chen, J. X., Zhou, X. J. (2015): Effects of various factors on the viv-induced fatigue damage in the cable of submerged floating tunnel. - Polish Maritime Research 22(4): 76-83.

[18] Maddock, I. (1999): The importance of physical habitat assessment for evaluating river health. - Freshwater Biology 41(2): 373-391.

[19] Maunder, M. N., Hinton, M. G., Bigelow, K. A., Langley, A. D. (2006): Developing indices of abundance using habitat data in a statistical framework. - Bulletin of Marine Science 79(3): 545-559.

[20] Mejia-Sanchez, F., Patricia Montenegro-Morales, L., Castillo-Cadena, J. (2018): Enzymatic activity induction of GST-family isoenzymes from pesticide mixture used in floriculture. - Environmental Science and Pollution Research 25(1): 601-606.

[21] Mohri, M. (1999): Seasonal change in bigeye tuna fishing areas in relation to the oceanographic parameters in the Indian Ocean. - IOTC Proceedings 2: 207-220.

[22] Morris, L., Ball, D. (2006): Habitat suitability modelling of economically important fish species with commercial fisheries data. - ICES Journal of Marine Science 63: 590-1603.

[23] Pedro, B. M. (2006): Fishing effort analysis and its potential to evaluate stock size. Reviews in Fisheries Science 14: 369-393.

[24] Qiu, Y., Zeng, X., Chen, T. (2008): Fisheries Resources and Fisheries Management in the South China Sea (in Chinese). - Ocean Press, Beijing.

[25] Shao, F., Chen, X. (2008): Relationship between fishing ground of Symlectoteuthis oualaniensis and sea surface height in the northwest Indian Ocean. - Marine Sciences 32: 88-92.

[26] Siriraksophon, S., Nakamura, Y., Sukramonkkol, N.(2001a): Exploration for the Purpleback Flying Squid, Stenoteuthis oualaniensis Resources in the South China Sea. SEAFDEC/Training Department, Bangkok.

[27] Siriraksophon, S., Sukramongkol, N., Nakamura, Y. (2001b): Exploration of Oceanic Squid, Sthenoteuthis Oualaniensis Resources in the South China Sea, Vietnanmese waters. - In: Proceedings of the Third Technical Seminar on Marine Fishery Resources Survey in the South China Sea, Area IV: Vietnamese Waters. Special Paper No. SEC/SP/44. Southeast Asian Fisheries Development Center, Bangkok, pp. 181-197. 
[28] Skov, H., Humphreys, E., Garthe, S., Geitner, K., Grémillet, D., Hamer, K. C., Hennicke, J., Parner, H., Wanless, S. (2008): Application of habitat suitability modelling to tracking data of marine animals as a means of analyzing their feeding habitats. - Ecological Modelling 212(3): 504-512.

[29] Song, T. (2014): Relationship between Fishing Grounds of Ommastrephes bartramiand Satellite Altimeter Data in Northwestern Pacific (Dissertation). - Shanghai Ocean University, Shanghai.

[30] Swamy, M. M., Nagabhushana, B. M., Krishna, R. H., Kottam, N., Raveendra, R. S., Prashanth, P. A. (2017): Fast adsorptive removal of methylene blue dye from aqueous solution onto a wild carrot flower activated carbon: isotherms and kinetics studies. Desalination and Water Treatment 71: 399-405.

[31] Tian, S., Chen, X., Chen, Y., Xu, L., Dai, X. (2009): Evaluating habitat suitability indices derived from CPUE and fishing effort data for ommatrephes bratramii in the northwestern Pacific Ocean. - Fisheries Research 95(2): 181-188.

[32] United States Fish and Wildlife Service (1981): Standards for the Development of Habitat Suitability Index Models. - United States Fish and Wildlife Service, ESM 103. Release 181. Department of the Interior, Washington, DC.

[33] Yan, Y., Feng, B., Lu, H., Lai, J., Du, S. (2012): Fishery biology of purpleback flying souid Sthenoteuths oualaniensis in northern sea areas around Nansha islands in summer. - Oceanologia et Limnologia Sinica 43(6): 1177-1187.

[34] Yang, S. L., Zhang, Y., Zhang, H., Fan, W. (2015): Comparison and analysis of different model algorithms for CPUE standardization in fishery. - Transactions of the Chinese Society of Agricultural Engineering 31(21): 259-264.

[35] Yu, W., Chen, X. (2012): Analysis on habitat suitability index of Sthenoteuthis oualaniensis in Northwestern Indian Ocean from September to October. - Journal of Guangdong Ocean University 32(6), 74-80.

[36] Yu, W., Chen, X., Yi, Q. (2016): Relationship between spatio-temporal dynamics of neon flying squid Ommastrephes bartramii and net primary production in the northwest Pacific Ocean. - Acta Oceanologica Sinica 38 (2): 64-72.

[37] Yuan, Y., Xu, Y., Arulrajah, A. (2017): Sustainable measures for mitigation of flooding hazards: a case study in Shanghai, China. - Water 9: 3105.

[38] Zainuddin, M., Kiyofuji, H., Saitoh, K., Saitoh, S. I. (2006): Using multi-sensor satellite remote sensing and catch data to detect ocean hot spots for albacore (thunnus alalunga) in the northwestern north pacific. - Deep Sea Research Part II Topical Studies in Oceanography 53(3): 419-431.

[39] Zhang, H., Zhang, S. M., Cui, X. S., Yang, S. L., Hua, C. J., Ma, H. Y. (2015a): Spatiotemporal dynamics in the location of the fishing grounds and catch per unit effort (CPUE) for Chilean jack mackerel (Trachurus murphyi Nichols, 1920) from Chinese trawl fleets on the high seas of the southeast Pacific Ocean, 2001-2010. - Journal of Applied Ichthyology 31(4): 646-656.

[40] Zhang, J., Chen, Z. Z., Chen, G. B., Zhang, P., Qiu, Y. S., Yao, Z. (2015b): Hydroacoustic studies on the commercially important squid Sthenoteuthis oualaniensis in the South China Sea. - Fisheries Research 169: 45-51. 